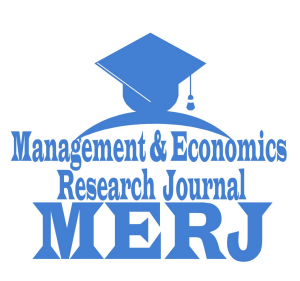

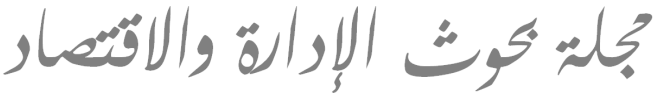

Management \& Economics Research Journal ISSN 2710-8856 (Online)

ISSN 2676-184X (Print)

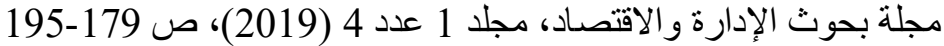

Management \& Economics Research Journal, Vol. 1 No. 4 (2019), pp. 179-195

doi) https://doi.org/10.48100/merj.v1i4.68

(D) Check for updates

\section{ممارسة التدقيق الداخلي على ضوء المعاييز الدولية في المؤسسات الاقتصادية العمومية: دراسة حالة مؤسسة مناجم الفوسفات تبسة (SOMIFHOS)}

\author{
أسماء معيفي 1 1 \\ 1 باحثة دكتور راه، جامعة فرحات عباس سطيف (الجز ائر ) \\ $\triangle$ asma.maifi@gmail.com
}

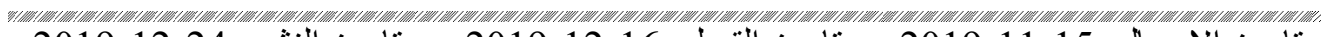

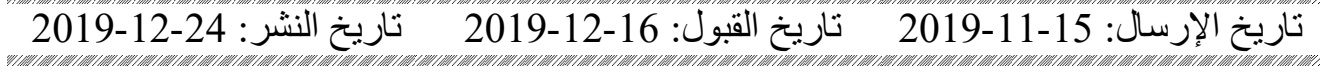

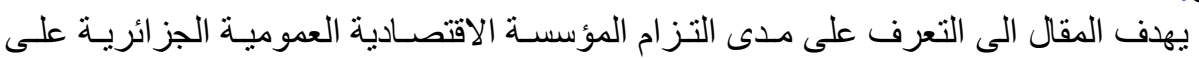

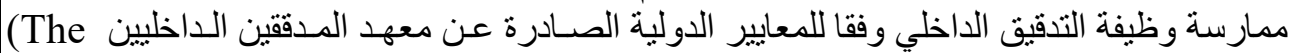
(Institute of Internal Auditors)

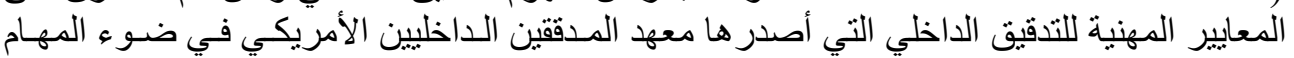

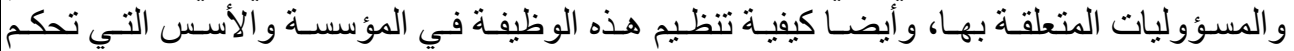

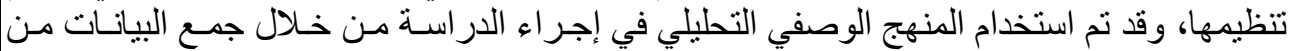

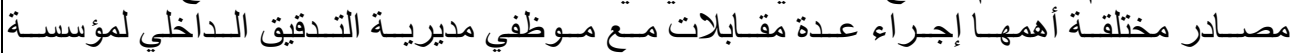

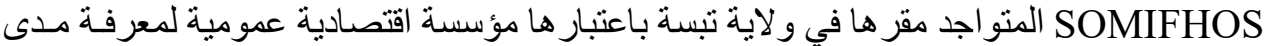

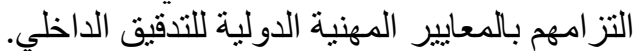
الكلمات المفتاحية: التدقيق داخلي، معايير التدقيق الداخلي الدولية، المؤسسات العمومية الاقتصادية. تصنيف جال: M42, J81.

• • المؤلف المراسل: [ه asma.maifi@gmail.com 
مجلـة بحوث الإدارة و الاقتصاد المجلد 01 العدد 04 (2019) ص 179-195 ص

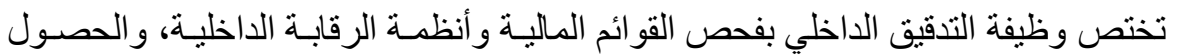

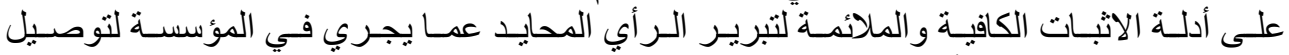

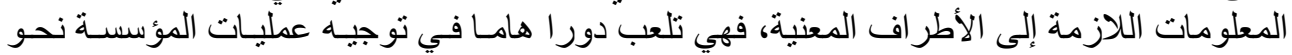

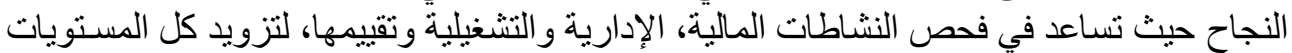

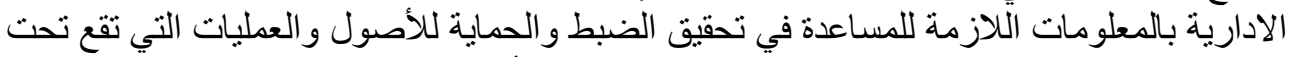

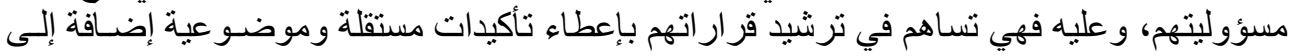

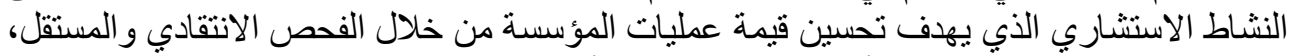

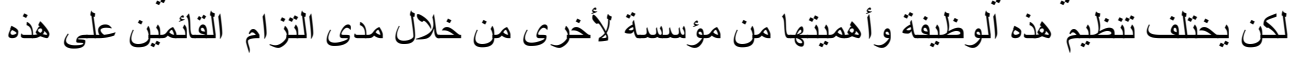

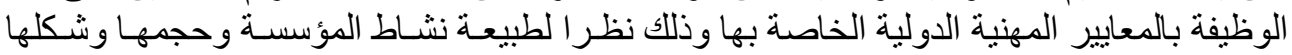
من خلال هذا المقال سيتم الوقوف على كيفية ممارسة وظيفة التدقيق الداخلي وفقا للمعسيير

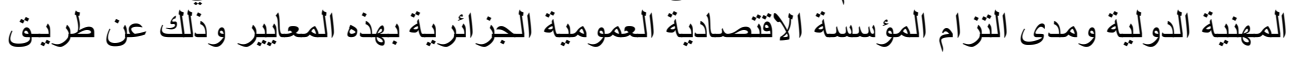

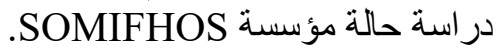

1.1 ما مدى مطابقة ممارسـة التدقيق الداخلي في المؤسسـة الاقتصـادية العموميـة الجزائريـة

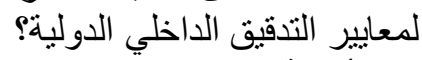
2.1

ـ ما المقصود بالتدقيق الداخلي؟ وماهي المعايير الدولية للتدقيق الداخلي؟

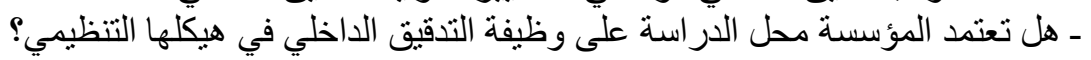

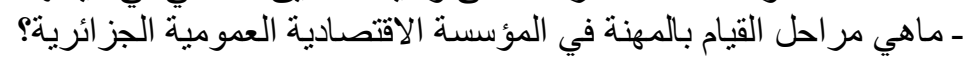
3.1 فرضيات البحث

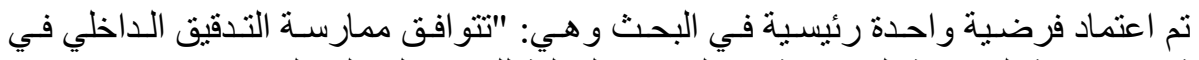

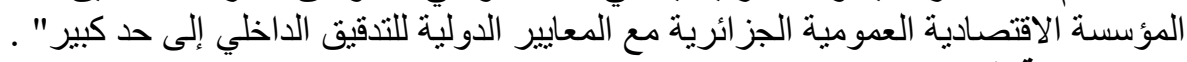
4.1

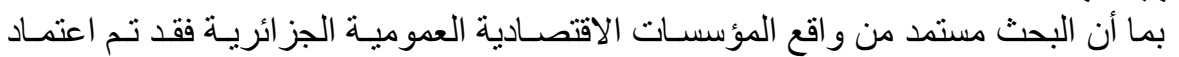

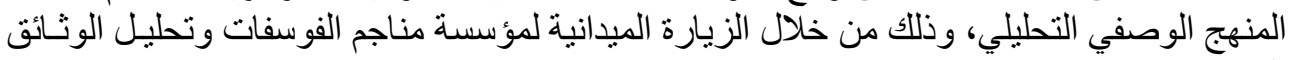
المقدمة من طرفهم.

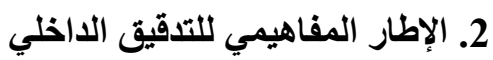

$$
\text { سيتم التطرق إلى تعريف التدقيق الداخلي، أهدافه و أنواعه. }
$$

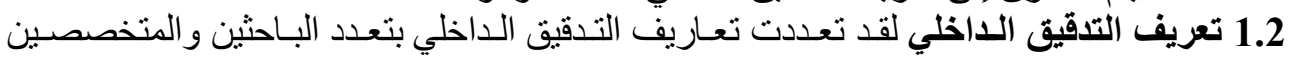

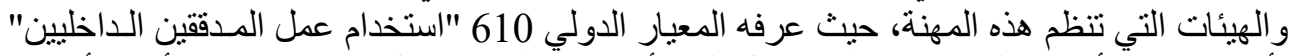

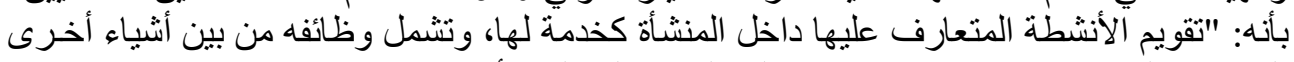

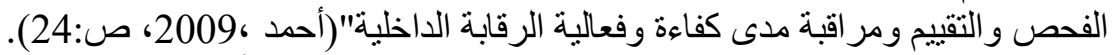

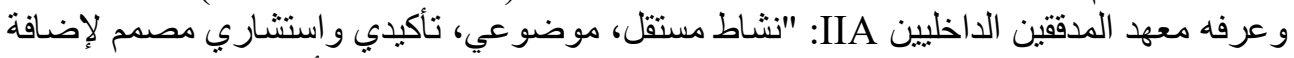

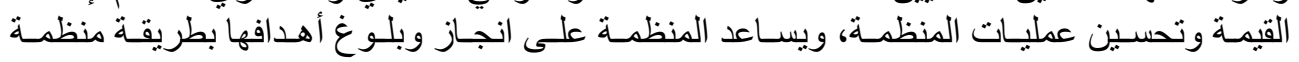


(Pickett, 2003, p: "و ونضبطة لتقييم وتحسين فعالية إدارة المخاطر و الرقابة و عمليات الحوكمـة

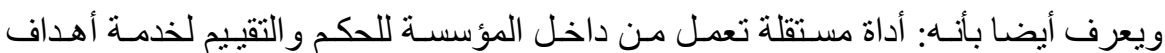

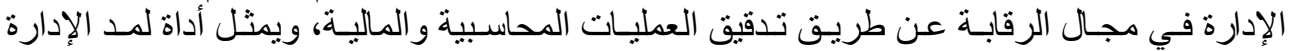
بالمعلومات فيما يتعلق بالنواحي الآني الآتية: -

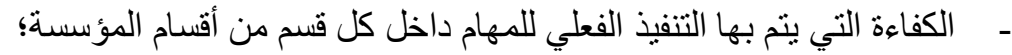

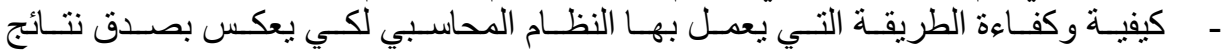

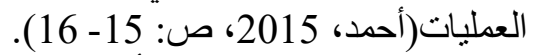

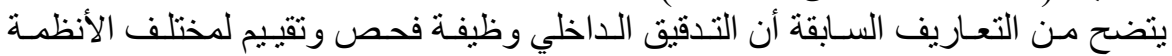

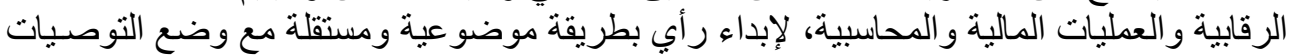

\section{2 أهداف التدقيق الاخلي:}

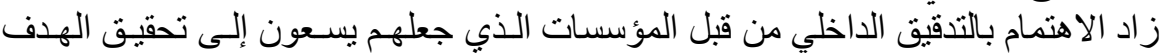

الرئيسي للتدقيق الداخلي الذي حدده معهد المدققين الداخليين الألئ الأمريكي وهو :

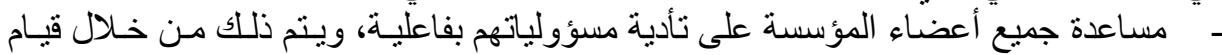

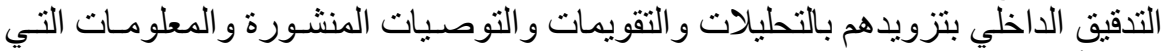

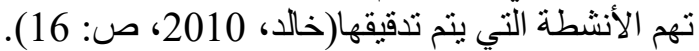
وأيضا اهداف أخرى ثنانوية نذكر منها:

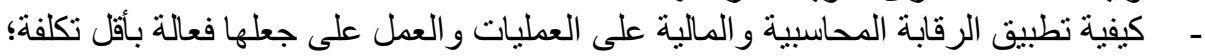
-

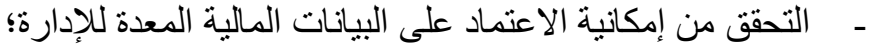

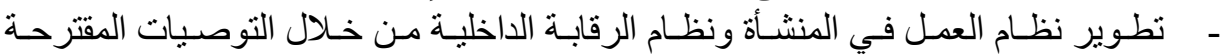

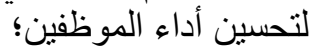

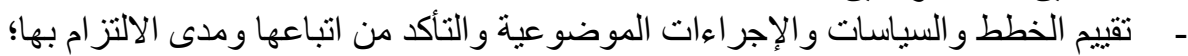

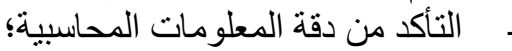

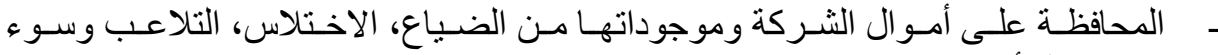

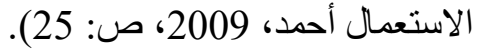

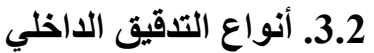

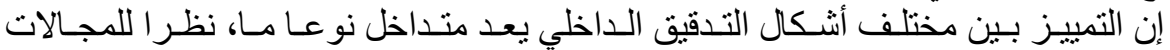

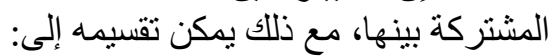

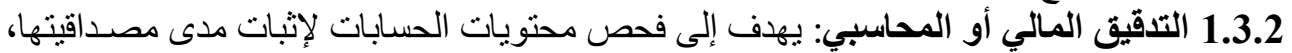

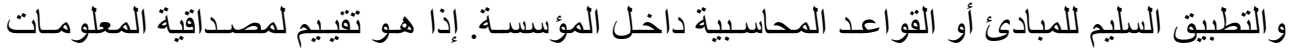
و التحقق من سلامة إجراءات التسجيل المحاسبي، بحيث تقليديا كانت تتحصر ألتور عمليات التدقيق في هذا الثكل.

2.3.2 تدقيق العمليات: يكون مجال الفحص في هذا النـوع و اسـع جدا، لأنـه يضـم جميع أنشطة المؤسسة، ويأخذ شكلين هما:

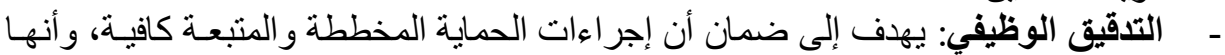

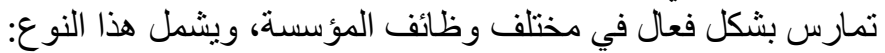
ل و وظائف واسعة جدا: الثراء، المبيعات، الإنتاج، الموارد البشرية؛ 


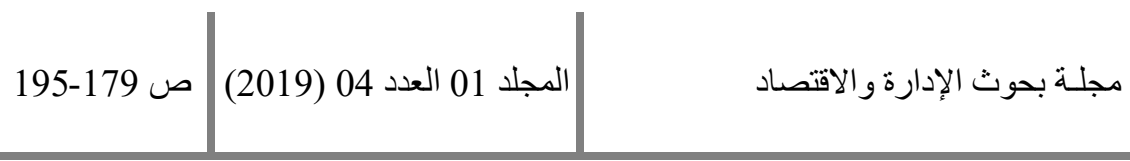

ل و وظائف محددة: البعثات، تسبير المخزونات.

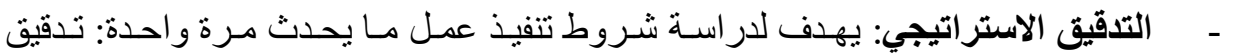

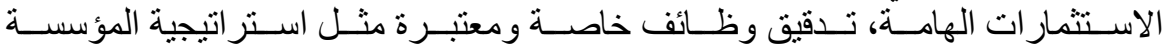
.(Khelassi,2007, p: 94-95) و هناك ثناثة أعمار أو مستويات لـذا النوع من التدقيق الداخلي الذي بشمل مختلف وظـائف المؤسسة، حسب ما يوضحه الجدول التالي:

\begin{tabular}{|c|c|c|c|c|c|c|c|c|}
\hline \multirow[t]{4}{*}{ و التوريد الخارجيات } & الاجتماعية & القانونية & النقل & الصعيانة & الإنتاج & التقنية & المحاسبة & \\
\hline & & & & & & & & تدقيق المطابقة \\
\hline & & & & & & & & تدقيق الفعالية \\
\hline & & & & & & & & التدقيق الإداري \\
\hline
\end{tabular}

Source : (khelassi, 2007, p : 95)

3.3.2 تدقيق المهام الخاصة أو لأغراض خاصة:

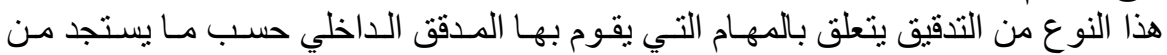

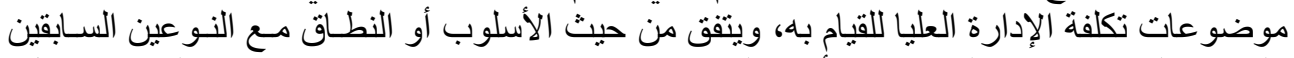
ولكنه يختلف من ناحية التوقيت، إذ أنه غالبا ما يكون فجائيا و غير مدرج ضئ ضمن خطة التدقيق(كمال،

2009، ص: 24)

\section{3. المعايير الدولية للتدقيق الداخلي}

أصدر معهد المدققين الداخليين الأمريكي IIA معابير التدقيث الداخلي سنة 1978م، والتي التي

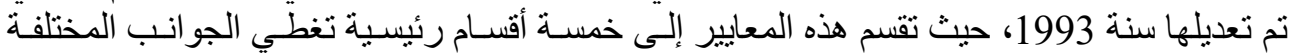

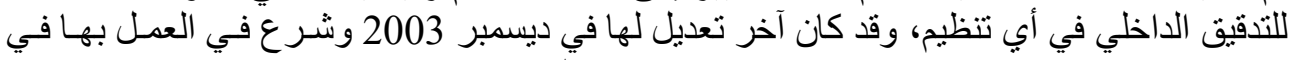

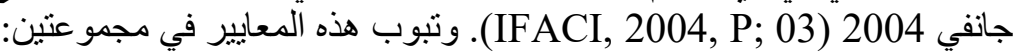

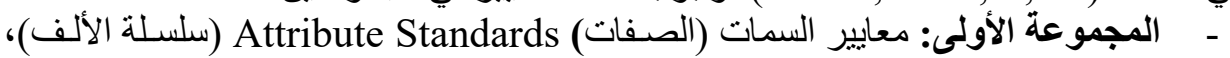

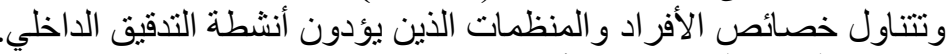

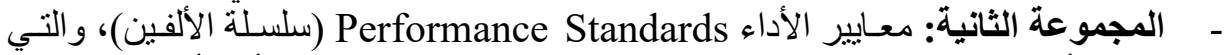

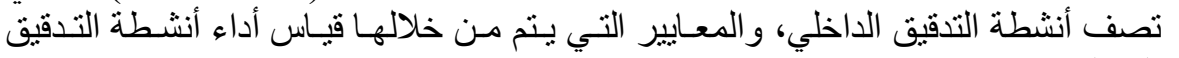

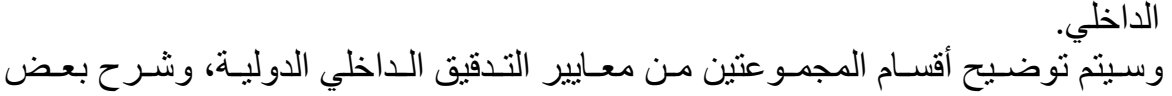
المعايير الرئيسية في الجداول المو الية.

جدول رقم 2: معايير السمات (سلسلة الألف)

\begin{tabular}{|c|c|c|c|}
\hline \multicolumn{3}{|c|}{ معايير السمات } & المجمو عة الأولى \\
\hline & & الغرض و السلطة و المسؤولية & 1000 \\
\hline & & الاستقلالية و الموضو عية & 1100 \\
\hline & الاستقلال التنظيمي & 1110 & \\
\hline & الموضو عية الفردية & 1120 & \\
\hline & تهديد الاستقلال أو الموضوعية & 1130 & \\
\hline & & الكفاءة و العناية المهنية اللازمة & 1200 \\
\hline
\end{tabular}


ممارسة التدقيق الداخلي على ضوء المعايير الدولية في المؤسسات الاقتصادية

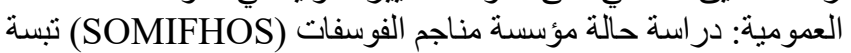

\begin{tabular}{|c|c|c|c|}
\hline & الكفاءة المهنية & 1210 & \\
\hline & العناية المهنية اللازمة & 1220 & \\
\hline & التطوير المهني المستمر & 1230 & \\
\hline & & تأكيد الجودة وبر امج التحسين & 1300 \\
\hline & تقييم بر امج الجودة & 1310 & \\
\hline التقييم الداخلي & 1311 & & \\
\hline التقييم الخارجي & 1312 & & \\
\hline & التقرير عن بر امج الجودة & 1320 & \\
\hline & استخدام عبارة لقد دقفنا وفق المعايير & 1330 & \\
\hline & الإفصاح عن عدم الاذعان & 1340 & \\
\hline
\end{tabular}

المصدر: (جمعة، 2011، ص: 84-85)

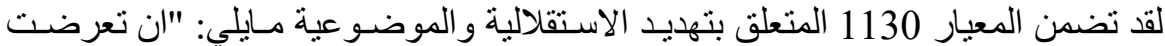

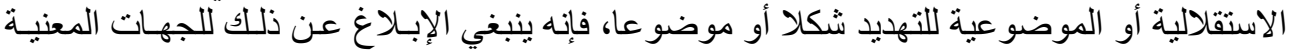

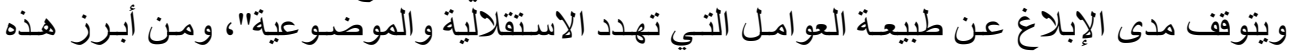

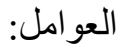

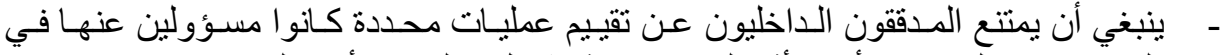

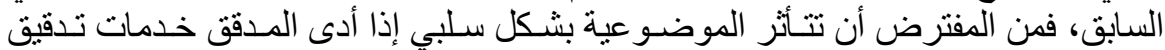

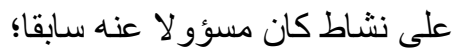
ينبغي ان يكون هنالك طرف خارجي مسؤول عن تقييم الوظائف التي يؤديها كبير المدققين؛

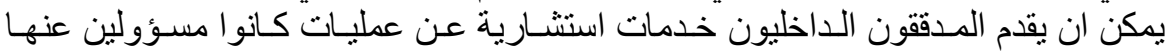

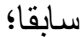
- إذا كان من المحتمل ان يقع ما يهدد استقلالية او موضوعية المدققين الـداخليين عند أدائهم

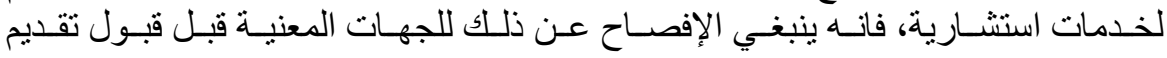

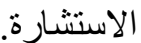

كما تضمن المعيار 1220 المتعلق بالعناية المهنية اللازمة مايلي:

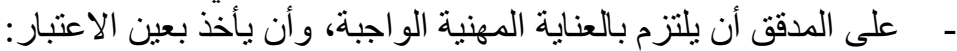

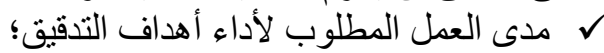

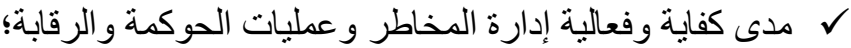

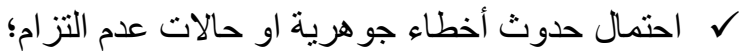

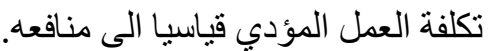

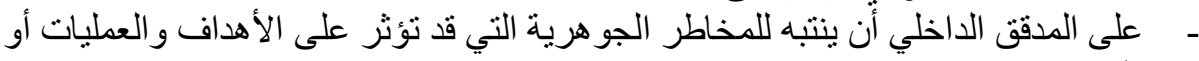

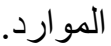
- على المدقق الداخلي أن يبذل العناية المهنية الو اجبة اثناء قيامه بعمله الاستشاري، بأن يأخذ

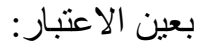

ل حاجات وتوقعات العميل بما في ذللك توصبيل النتائج إليه؛

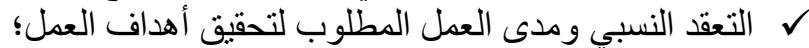

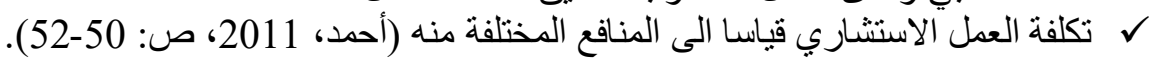
أما الجدول الثاني يوضح المجموعة الثانية من معايير التدقيق الداخلي و المتمثلة في سلسلة الألة

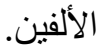




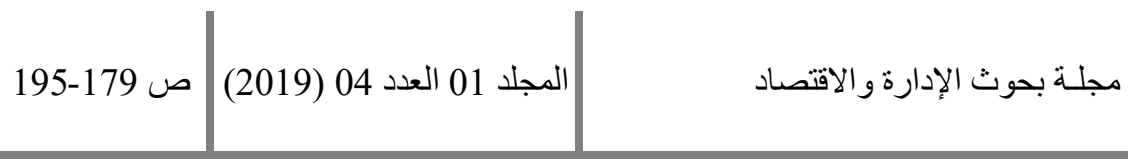

جدول رقم 3: معايير الأداء (سلسلة الألفين)

\begin{tabular}{|c|c|c|c|}
\hline \multicolumn{3}{|c|}{ معايير الأداء } & \multirow{2}{*}{ المجمو عة الثانية } \\
\hline & & إدارة أنشطة التدقيق الداخلي & \\
\hline & التخطيط & 2010 & \\
\hline & الاتصـال و المو افقة & 2020 & \\
\hline & إدارة الموارد & 2030 & \\
\hline & السياسـات و الإجر اءات & 2040 & \\
\hline & التنسيق & 2050 & \\
\hline & التقرير الى المجلس و الإدارة & 2060 & \\
\hline & & طبيعة العمل & 2100 \\
\hline & إدارة المخاطر & 2110 & \\
\hline & الرقابة & 2120 & \\
\hline & الحوكمة & 2130 & \\
\hline & & تخطيط المهمة & 2200 \\
\hline & اهداف المهمة & 2210 & \\
\hline & نطاق المهمة & 2220 & \\
\hline & تخصيص موارد المهمة & 2230 & \\
\hline & برنامج عمل المهمة & 2240 & \\
\hline & & أداء المهمة & 2300 \\
\hline & تحديد المعلومات & 2310 & \\
\hline & التحليل و التقييم & 2320 & \\
\hline & تسجيل المعلومات & 2330 & \\
\hline & الاشر اف على المعلومات & 2340 & \\
\hline & & توصيل النتائج & 2400 \\
\hline & معايير التوصبيل & 2410 & \\
\hline & جودة الاتصسال & 2420 & \\
\hline و الخطو & 2421 & & \\
\hline & الإفصاح عن عدم الإذعان & 2430 & \\
\hline & نشر النتائج & 2440 & \\
\hline & & بر امج المر اقبة & 2500 \\
\hline & & قبول الإدارة للمخاطر & 2600 \\
\hline
\end{tabular}

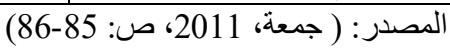

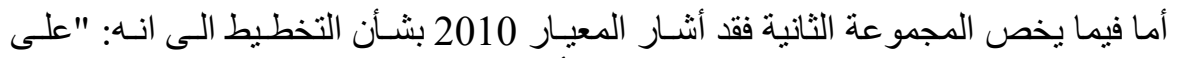

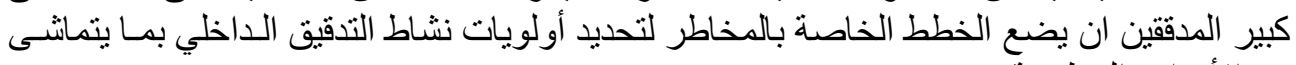
مع الأهداف التنظيمية".

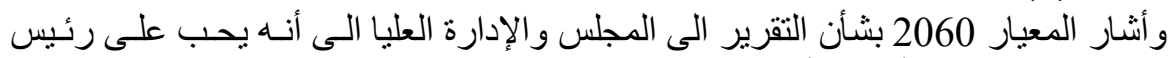

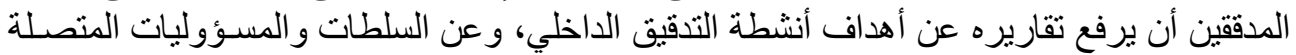

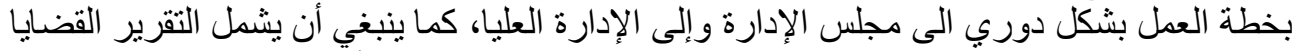

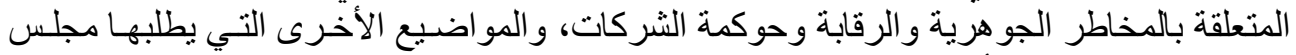

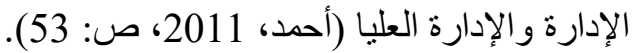
أما المعيار 2400 الخاص بتوصيل النتائج الخاصة بالتدقيق الداخلي فقد تضمن الآتي: 


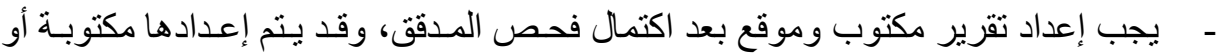

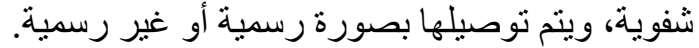
- يلزم مناقتشة النتائج و التوصيات مع المستويات الإدارية المعنية قبل إصدار التقرير النهائي

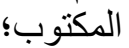

- أن توصف التقارير التي يصدر ها التدقيق الداخلي بالموضو عية والوضوح و والاختصار؛

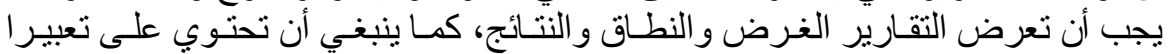

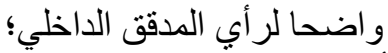

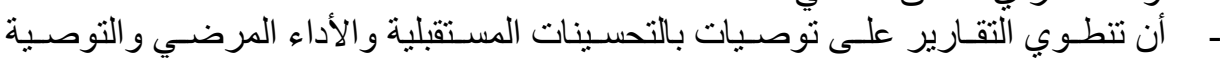

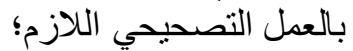
قد يتضمن التقرير وجهات نظر للأفر اد محل التدقيق حول النتائج و التوصيات التي يحتويها

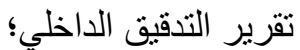

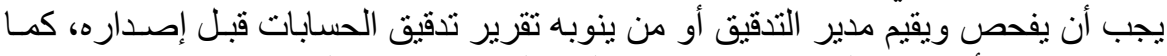
يجب تحديد الأشخاص الذين سوف يوزع عليهم التقرير (سامي ولؤي، لتئ 2010، ص: 209-

\section{4. ممارسة التتقيق الاخلي بمؤسسة مناجم الفوسفات SOMIFHOS بتبسة}

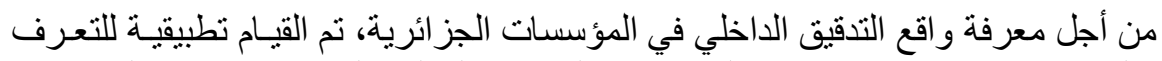

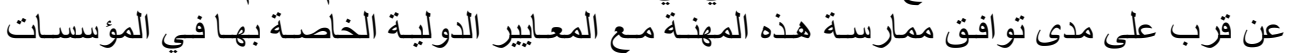

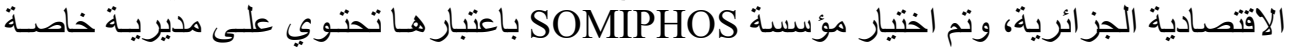
بالتدقيق في هيكلها التنظيمي. SOMIPHOS التعريف بمؤسسة هئنة

هي مؤسسة مناجم الفوسفات " SOMIPHOS" وليدة تقسيم المؤسسـة الوطنيـة للحديـ

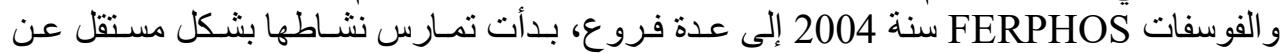

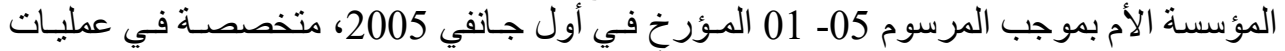
استخر اج، معالجة وتسويق الفو سفات لمختلف الأسو أق داخلي أليا وخار جيا.

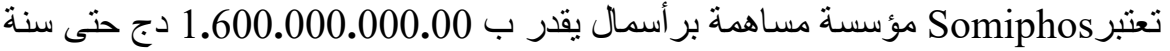

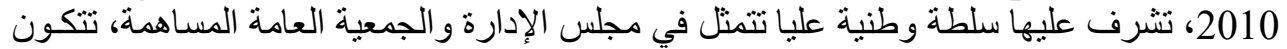

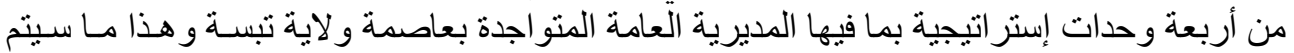
توضيحه في الجدول التالي: 
|المجلا 01 العدد 04 (2019) ص 179-195 ص

مجلـة بحوث الإدارة و الاقتصاد

جدول رقم 4: وحدات مناجم الفوسفات

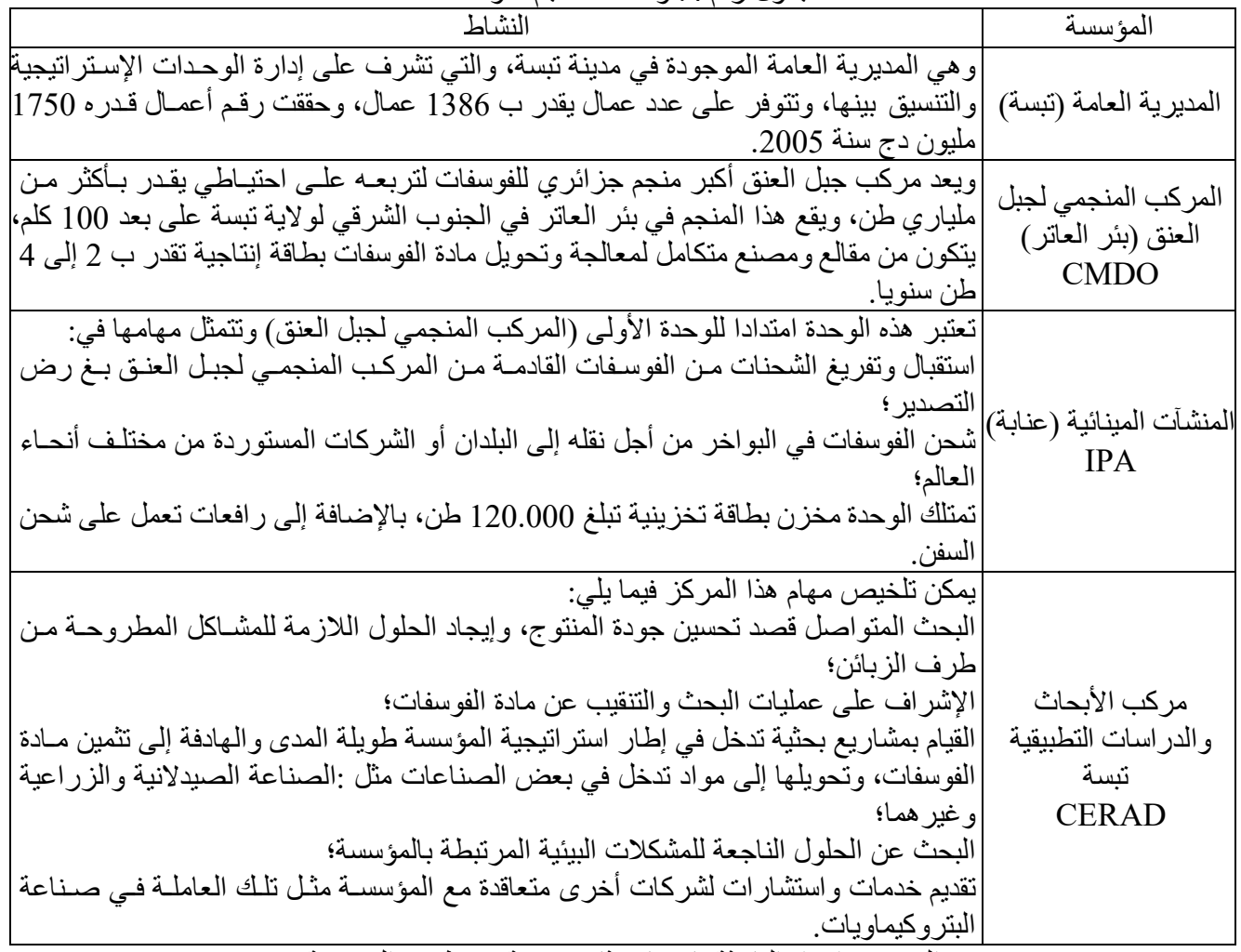

المصدر : اعداد الباحثة باعتماد وثائق مقدمة من طرف المؤسسة

2.4.الهيكل التظيمي لمؤسسة SOMIPHOS 
ممارسة التدقيق الداخلي على ضوء المعايير الدولية في المؤسسات الاقتصادية

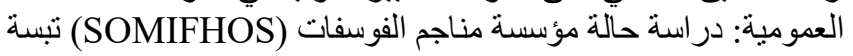

\section{شكل رقم 1: الهيكل التنظيمي لمؤسسة SOMIPHOS}

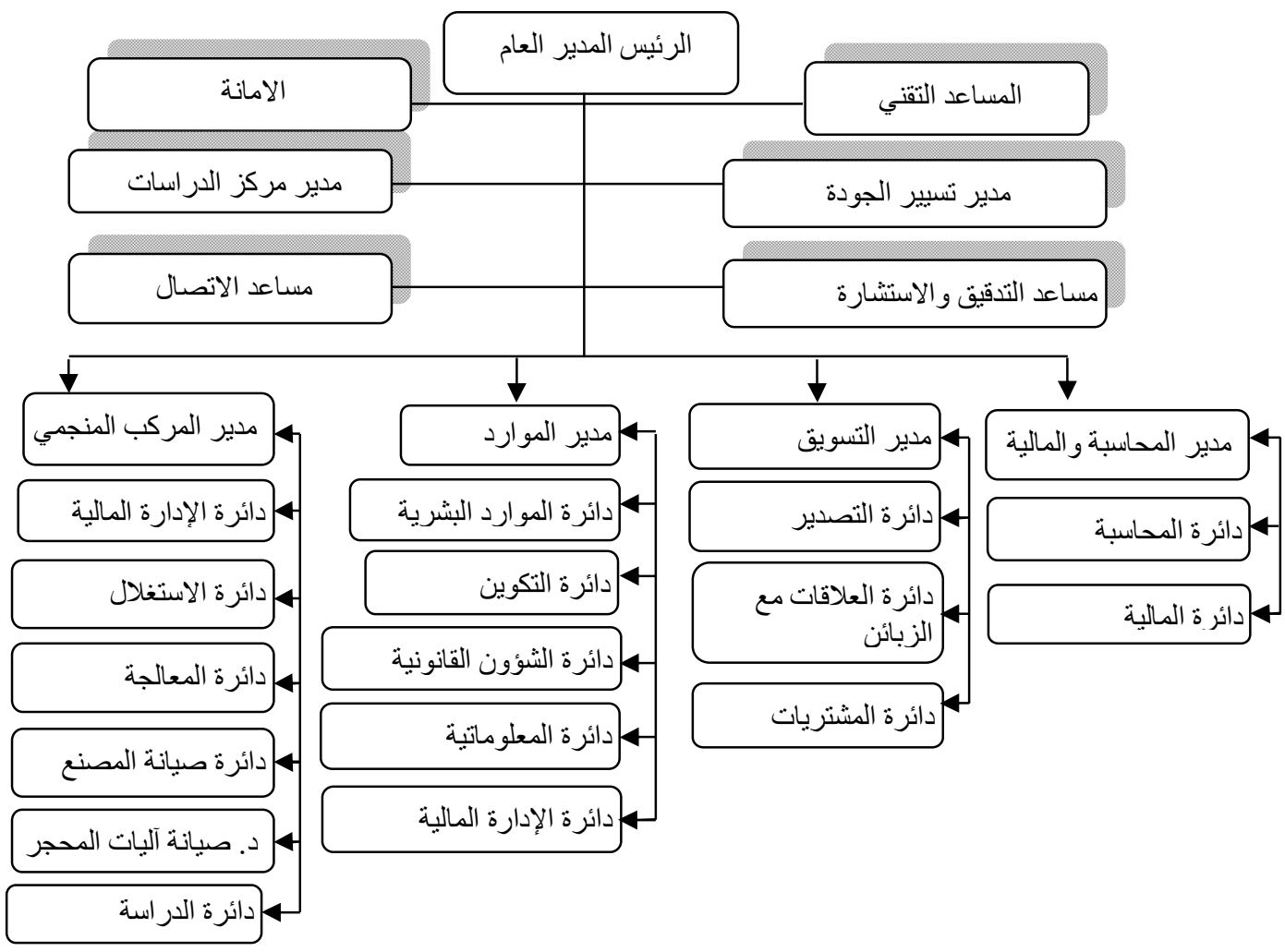

\section{المصدر : وثائق مقدمة من طرف المؤسسة}

سـيتم فقط ذكر مهـام مصـلحة مسـاعد التـدقيق الـداخلي والاستشـارة نظـر ا للغـرض مـن

مساعد التدقيق و الاستشارة: عملية التدقيق تحتل حيز الهاما في استر اتيجية المؤسسة لكونها

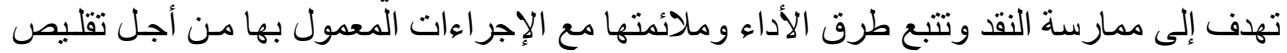
نقاط الضعف وتدعيم نقاط القوة. لللك فمساعد التدقيق يقوم بأعماله تحت إثر اف الف المدير العام وفي نهايـة كل مرحلـة يقدم

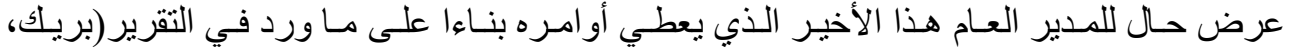

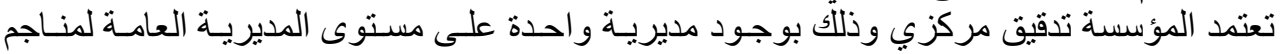

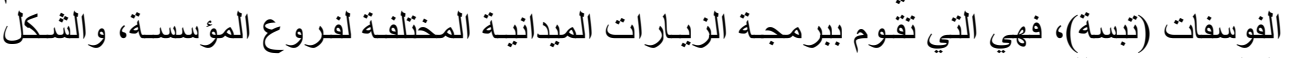
التالي يوضح ذلك: 


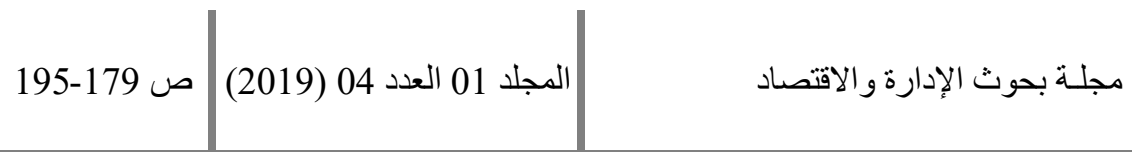

شكل رقم 2: تموضع التدقيق الداخلي بمؤسسة SOMIPHOS

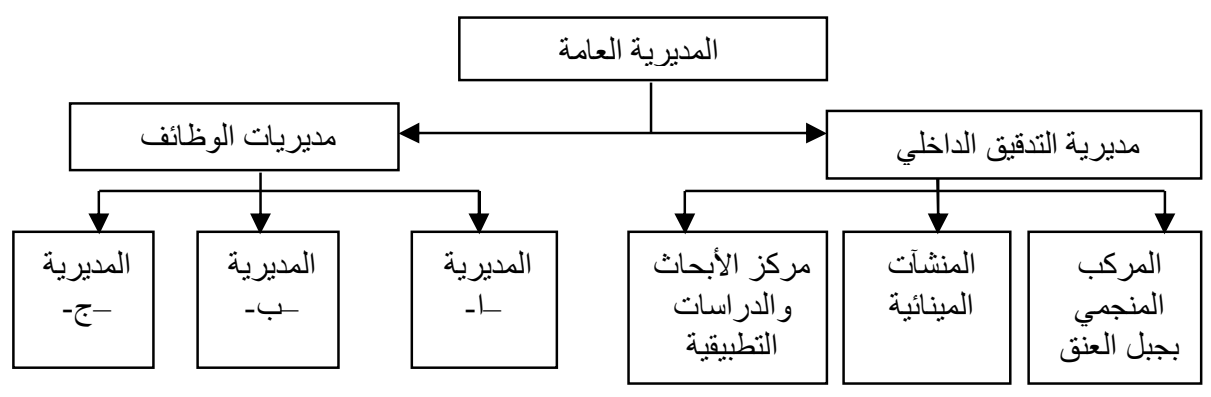

المصدر : معلومات مقدمة من طرف المؤسسة

كما يعمل بمديرية التدقيق الداخلي عدة مـوظفين يشـرف عليهه مدقق رئيس والذي بهنت

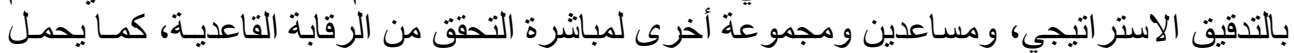

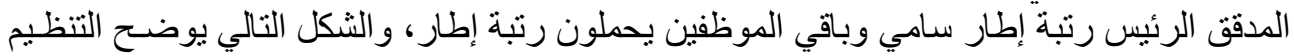
الداخلي للمديرية.

شكل رقم 3: المستويات التنظيمية للتدقيق الداخلي بمؤسسة SOMIPHOS

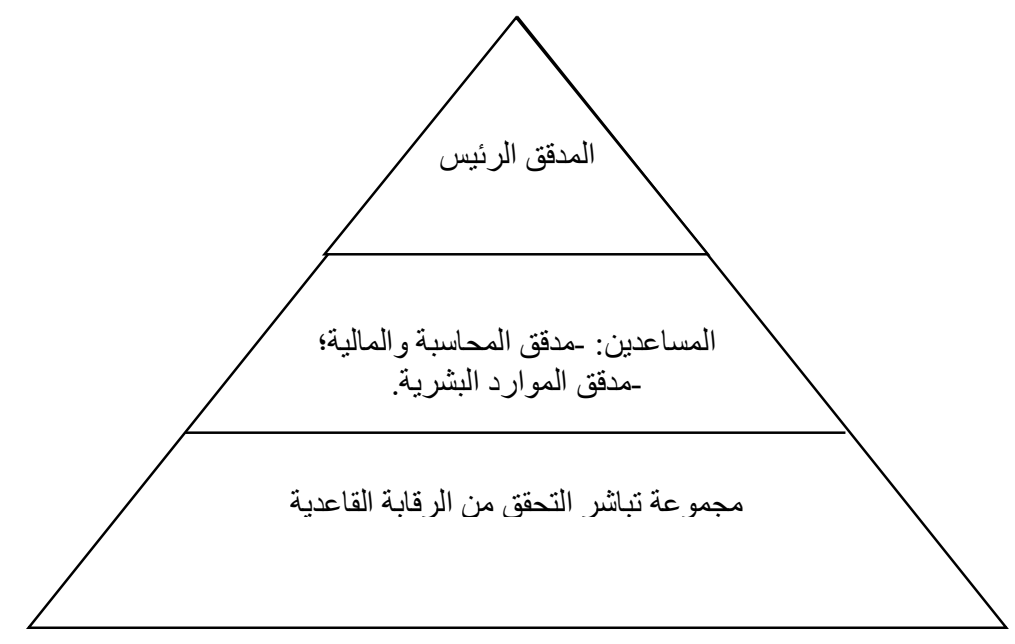

المصدر : من إعداد الباحثة اعتمادا على المعلومات المقدمة من المؤسسة

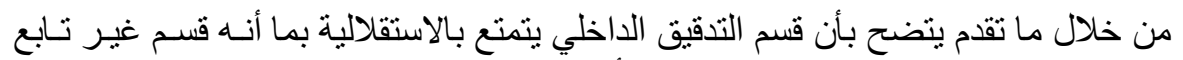

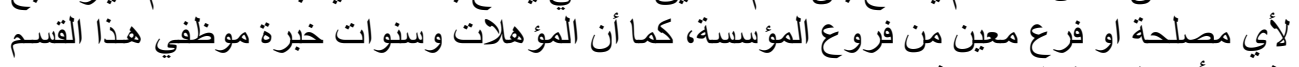
يثبت بأنهم ذوي كفاءة مهنية. 
ممارسة التدقيق الداخلي على ضو ء المعايير الدولية في المؤسسات الاقتصادية

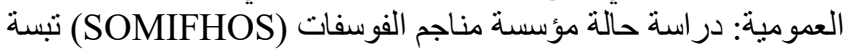

\section{Somiphos 4.4 مراحل القيام بعملية التدقيق الداخلي في مؤسسة 1.4.4 مرحلة التخطيط للمهرة:}

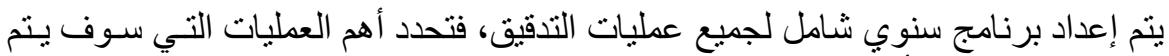

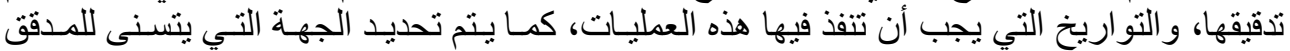

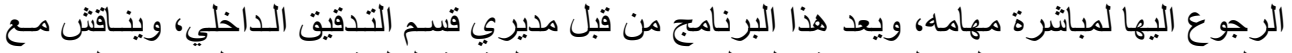

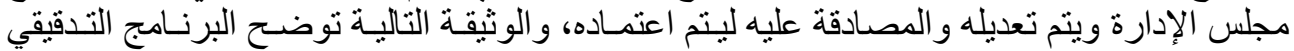
لسنة 2014 للمؤسسة (بريك، 2015).

\section{الوثيقة رقم1: برنامج التدقيق لسنة 2014}

\section{Programme 2014:}

Le programme 2014 a pris en considération huit $(08)$ processus majeurs pour l'ensemble des unités opérationnelles et managériales de l'entreprise à savoir :

- Ressources humaines,

- Comptabilité et finances,

- Achats et gestion des stocks,

- Les investissements

- La commercialisation,

- La production,

- La maintenance,

- Le juridique.

Le programme comporte 24 missions d'audit et 16 missions d'audit de suivi pour un volume de travail sur terrain de 157 jours ouvrables.

\section{PROGRAMME D'AUDIT POUR L'EXERCICE 2014}

\begin{tabular}{|c|c|c|c|c|c|c|c|c|c|c|c|c|c|}
\hline Désignations des Audits & 01 & Oz & 03 & 04 & 05 & 06 & 07 & 08 & a9 & 10 & 11 & 12 & Total \\
\hline 01/Ressources Humaines & $\varnothing$ & - & - & (e) & 53 & $\varnothing$ & - & & 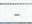 & - & S.1 & - & 04 \\
\hline 02/Achats et gestion des stacks & - & - & - & (c) & 53 & $\varnothing$ & - & & - & $=$ & 51 & - & 04 \\
\hline $03 /$ Investissements & - & - & - & (c) & & - & $\cdot$ & & $>$ & 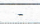 & - & - & 03 \\
\hline 04/Commercial \& Shipping & $=$ & $=$ & - & - & 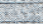 & - & - & & (c) & - & - & 52 & 02 \\
\hline o5/Production \& Embarquement & $=$ & $=$ & - & $=$ & & - & - & & - & - & $\$ 2$ & - & 02 \\
\hline as/Maintenance & - & - & - & $=$ & 115 & - & $=$ & $2]$ & $=$ & - & - & - & 02 \\
\hline ap/Juridique & (c) & - & $=$ & - & 53 & - & - & (18: & - & - & - & - & 03 \\
\hline as/Comptabilite et Finances & - & - & - & - & 10 & - & - & 1.0 & - & 0 & $\varnothing$ & - & 04 \\
\hline 09/Spécificues & & & & & & & & & & & & & \\
\hline TOTAL & 02 & 03 & 03 & 03 & 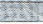 & 03 & 03 & 4. & 03 & 02 & 01 & 01 & 24 \\
\hline
\end{tabular}

- CMDO. : IPA, $\varnothing$ : CERAD, (D): DUS/DG

$\varnothing$ : Audit de suivi CERAD, 53 : Audit de suivi de 03 unités

$O$ : risque majeur, $O$ : risque modéré, $O$ : risque mineur,

Le Directeur d'Alidir Irrtentige A.BENKHEBBNB

المصدر : وثيقة مقدمة من قسم التدقيق الداخلي

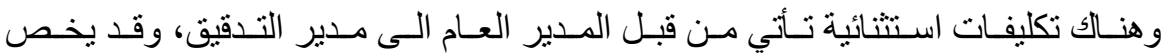
هذا التكليف عملية ما وقع فيها لبس أو ظهور بعض الأخطاء أو وجود انحر افات كبيرة.

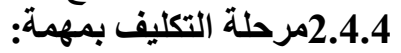

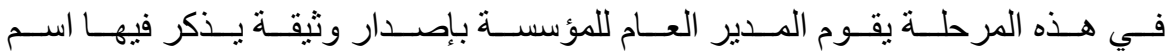

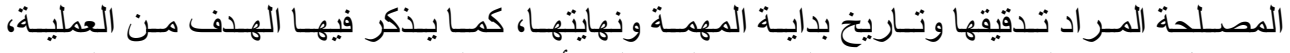

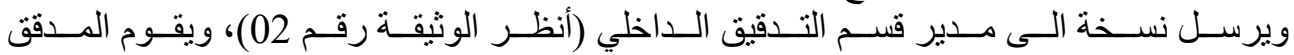


المجلد 01 العدد 04 (2019) ص 179-195 ص

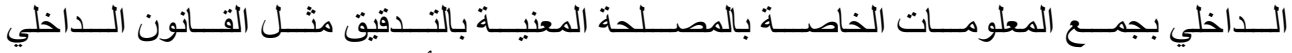

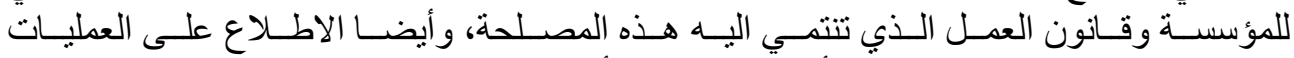

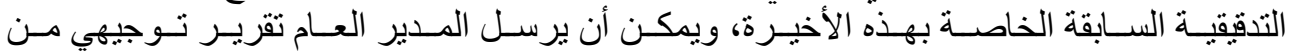
شأنه تحديد نطاق العملية التدقيقية (بريك، 2015).

الوثيقة رقم 2: تكليف بمهمة رقابة وفحص

FERPHOS (2roup REF = 3 XैDG/DPR/NG/2O13

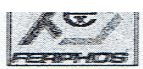

\section{sontrifas spa}

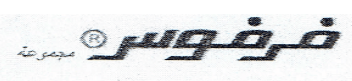

TIEBESSA UE 28/10/2013

Monsieur
He Directeur de I" Awdit Intherne

Os:1ET: Mission de contirable et de vérification.

Monsieur lle Directreur.

Nous wous demandons d"arganiser et de réciliser, darns lies meilleurs dúlois, une mission de contrable el de vénification du processus chargé de la gestion des Ressouroes Hurmaines cupprabs du Complexe Minier de Djebell Onik.

Cette mission de vénilicatilion sera axée principalement sur le processus de gestion de lia formatiom clurcant lies exercices 2012 et 2013, depuis le lancementi du cothier des charges jusqu"a la récilisation el l"évaluation de l"efficacitté des actions de formmatiom ett mothormamentit :

* Qualité et conttenu des cahiers des charges:

* Comsultiations ett camtiacts avec les corganismes de formation :

* Documernts ar Registre de commerce, agrément, aftiestations......etc.

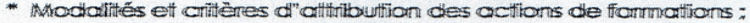

* Evaluation des actions réalisées........eta

De mêrne, it y al liew de s'irntermoger sur lies raisons de lla nom appliticattion de llinstruction de lia Direction Générale concemant la suspension de la relation avec

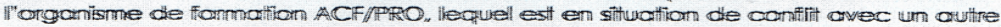
arganisme de fanmation, et ce jusqu'à la décision de la justice.

Meilieures soliuttations.

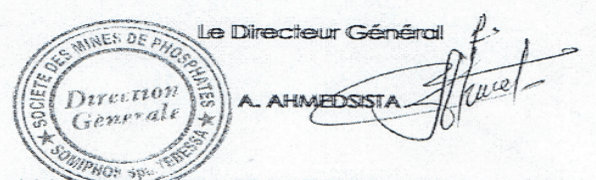

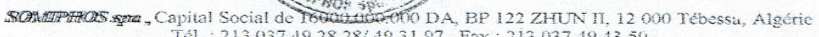

Tél. : 213.037 .49 .28 .28749 .31 .97 Fax: 213.037 .49 .43 .50

المصدر : وثيقة مقدمة من قسم التدقيق الداخلي

\subsection{4 مرحلة تنفيذ المهمة:}

في هذه المرحلة يتم عقد اجتماع افتتاحي بتم فيه الإعلان عن نهاية المرحلة التحضيرية

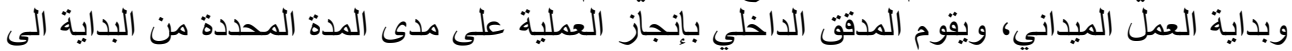

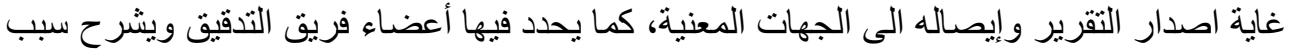
القيام بالعملية التدقيقية للمصلحة المراد تدقيقها، ويطلب من المسؤول عن المصلحة تقديم الهيكل التنظيمي الخاص بها، ويحاول أيضا إيجاد أجوبة للأسئلة التالية: - - كيف يتم توزيع المهام في هذه المصلحة ولجم 
ممارسة التدقيق الداخلي على ضو ألمعايير الدولية في المؤسسات الاقتصادية

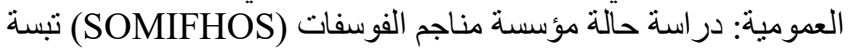

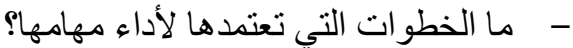

- - هل أن كل عملية مقسمة بين عدة أشخاص كل يؤدي دوره، أم أن كل عملية يقوم بها

$$
\text { شخص واحد من بدايتها لنهايتها؟ }
$$

بعدها يقوم بجمع الوثائق والمستندات و السجلات الخاصة بالمصات باتحة التي يتم تدقيقها،

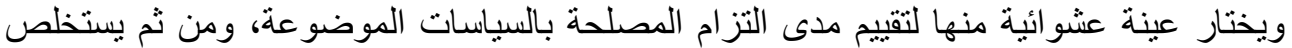

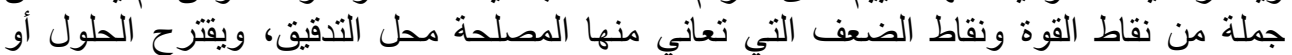
الإجر اءات التصحيحية التي من شأنها التخلص من النقائص، و هذا ما يتم كتابته في الوثيقة التالية:

$$
\text { الوثيقة رقم 3: بطاقة الثقييم }
$$

\begin{tabular}{|c|c|c|c|c|}
\hline & \multicolumn{4}{|c|}{ Niveau de rendement } \\
\hline & $\begin{array}{l}\text { Satisfait aux } \\
\text { exigences }\end{array}$ & $\begin{array}{l}\text { Satisfait } \\
\text { occasionnellem. }\end{array}$ & $\begin{array}{l}\text { Ne satisfait jamais } \\
\text { aux exigences }\end{array}$ & Observations \\
\hline \multicolumn{5}{|c|}{ Quantité de travail } \\
\hline \multicolumn{5}{|l|}{ Qualité de travail } \\
\hline \multicolumn{5}{|l|}{ Initiative } \\
\hline $\begin{array}{l}\text { Aptitude à la } \\
\text { communication }\end{array}$ & & & - & \\
\hline Ponctualité & & & $=$ & \\
\hline Autres & & & - & \\
\hline Evaluation finale & & & & \\
\hline
\end{tabular}

\section{FICHE D'EVALUATION}

Quelle sont les principales réalisations de l'intéressé

Quelle sont ses faiblesses:

Commentaires

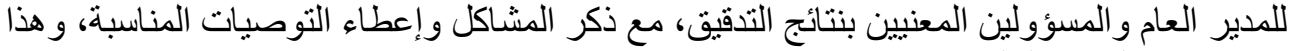

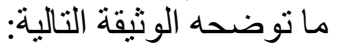




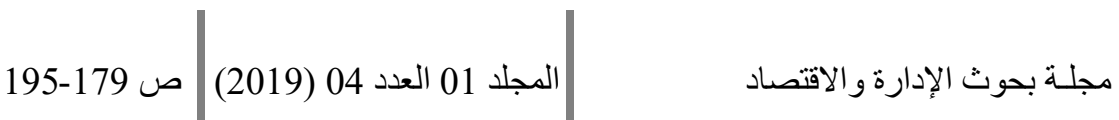

الوثيقة رقم 4: التقرير النهائي

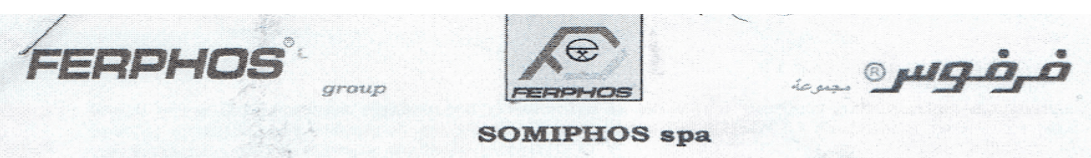

REF: /ASM/DG/2013

TEBESSA, LE 29/09/2013

A. Monsieur le Directeur du CERAD

Objet : note d'instructions.

Monsieur,

Faisant suite à la mission de vérification et control effectuée par la Direction d'Audit au niveau du CERAD et compte tenu les insuffisances et les fautes graves relevees dans les différents documents de gestion, nous vous demandons d'observer scrupuleusement ce qui diffêr

En matière de pointage

Les journalières de pointage doivent être renseignées soigneusement et d'une manière correcte, et seront signees conjointement par le pointeur et le chef du personnel. A cet effet nous vous demandons de reprendre les journalières des mois de juillet et. Aout 2013 et ce conformément aux procédures en vigueur.

En matiàre des dossiers administratifs.

Déclencher en urgence une operration de vérification et d'actualisation de l'ensemble des documents constituant les dossiers administratifs.

La tenue des dossiers et le mode de classement se fera selon les procédures administratives en vigueur.

Ea matière des primes et indemnités

L'attribution des primes et indemnité doit être conforme à la réglenentation en vigueur notamment la convention collective, les enregistrements nécessaires qui induisent une attribution salariale doivent être ordonnés par l'employeur par décision, le classement des documents dans les dossiers paie et administratif personnel est obligatoire.

A ce titre il ya lieu de procéder d'ares et déjà à une opération d'assainissement globale sur l'ensemble des rubriques paie de chaque agent (reprendre les listes des béméficiaires, examen des dossiers conformément a la convention collective, formalisme par des décisions)

\section{ICP $2012-2013$}

- Il vous est demandé impérativement de redresser et de corriger la situation de l'indernaité de congé payé et procéder à la retenue du trop percu pour les agents concernés.

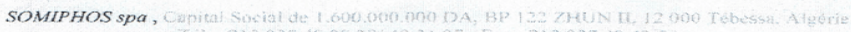


ممارسة التدقيق الداخلي على ضوء المعايير الدولية في المؤسسات الاقتصادية

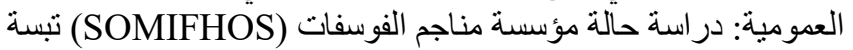

\section{Salaire unique}

Nous vous demandons également d'annuler la décision portant attribution du prime salaire unique, avec Rappel, au profit de madame conséquence à la retenue du trop perçu.

\section{Prime de transport}

- Mettre fin immédiatement aux attributions accordées contrairement à la convention collective.

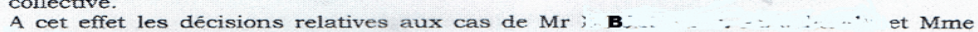
A cet effet les décisions relatives aux cas de $\mathrm{Mr}$. B
Toivent être annulees et procéder à un trop percu. Nuus vous demandons également de reprendre l'ensemble des cas de la dite prime (traitement des dossiers, actualisation des décisions et pièces justificatives).

En matière de la gestion des Frais des missions :

Le decompte et paiement des frais des missions se fera conformement à la procedure en vigueur, pour se faire il est indispensable de prendre attache avec la Direction des Ressources.

Mettre fin immédiatement à l'application de taux de $25 \%$ des frais de mission et procéder à un trop perçu pour les agents concernés

Corriger également le cas de Mme D ... ... ( ordre de mission $n^{\circ} 52 / 2013$ du $27 / 01 / 2013) 1$ intéressée doit rembourser le montant de l'indemnité kilométrique qui à été attribuée contrairement à la réglementation.

En matière d'organisation et de discipline :

Compte tenu les fautes graves commises par Mr $\mathbf{S} \ldots$ demandons de mettre fin aux fonctions de l'intéressé en qualité de chef du personnel du CERAD et ce jusqu' à nouvel ordre.

Durant cette période l'intéressê s'abstient d'exerces toute activités liées aux ressources humaine et d'utiliser les moyens de la paie.

L'intêrim de service đu personnel sera assuré par Mr H

A cet effet il vous est demandé de prendre toute vous dispositions pour la correction des dysfonctionnements constatés et l'amélioration de l'ensemble des actes de gestion au sein de votre unité.

Une opération de vérification et de contrôle sera effectuée quant à la prise en charge des instructions ci-dessus mentionnées, au moment opportun par la structure concernée.

Meilleures salutations.

Copie:

DR, Audit (P/suivi)

Le Directeur General

M.AHMED SISTA

المصدر : وثيقة مقدمة من قسم التدقيق الداخلي.

لقد سمح الوقوف على و اقع تنفيذ وظيفة التـدقيق الـداخلي للمؤسسـة محلـ الدر اســة الوثـائق المقدمة من طرفهم باستخلاص النتائج التالية:

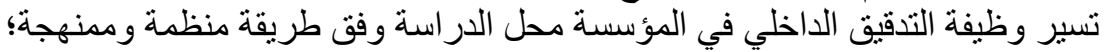

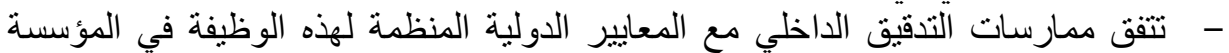

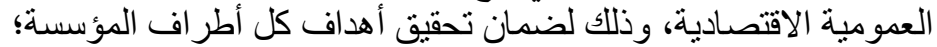

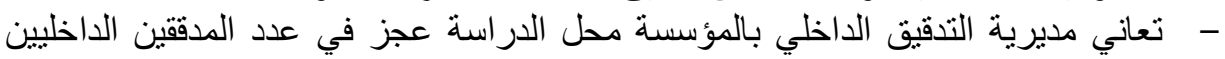
نظر ألصعوبة إيجاد الكفاءات المناسبة.

خلاصة

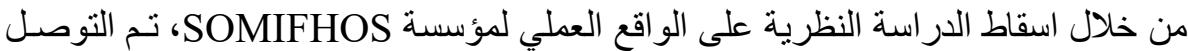

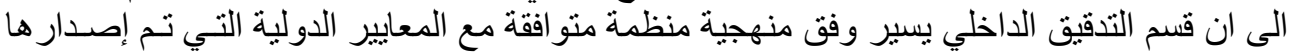

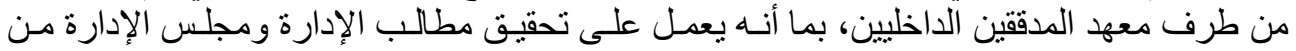


|المجلد 01 العدد 04 (2019) ص 179-195 ص

الناحية التقييمية، ليشمل بذلك مختلف وظائف المؤسسـة ومـديرياتها ليس حصـر ا فقط على الجانب

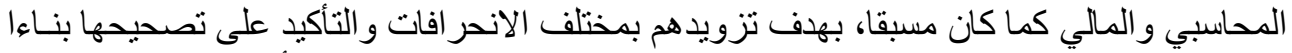

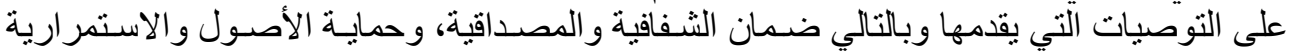
وهو الهدف الاسمى بالنسبة للمؤسسة.

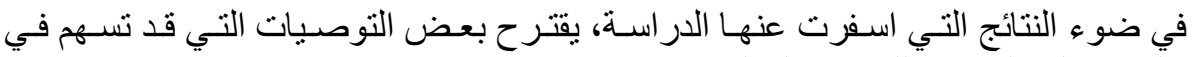
ممارسة التدقيق الداخلي وفقاً للمعايير الدولية، التئي وهي:

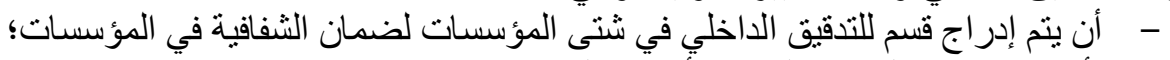

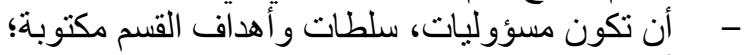
- - أن تهتم المؤسسات بعقد دور ات تكوينية وتدريبية للموظفين حول المعايير الدولية للتدقيق الداخلي، حتى يتم الإلمام بهاو ويسهل تطبيقها.

IFACI. (Février 2004). Institut de l'Audit Interne, Normes internationales pour la pratique professionnelle de l'audit interne.

Pickett, KH. Spencer. (2003). The internal auditing handbook, $2^{\text {nd }}$ edition, Wiley, USA.

Khelassi, R. (2007). L'audit interne -Audit opérationnel-,2 $2^{\text {eme }}$ édition. Alger : Houma éditions Alger.

أحمد، حلمي جمعة. (2009). المـدخل إلى التدقيق و التأكيد الحديث (الطبعـة الأولى). الأردن: دار الصـفاء للنشـر ورالتوزيع. جميع.

أحمد، حلمي جمعة. (2011). التدقيق الداخلي و الحكومي (الطبعة الأولى). الأردن: دار الصفاء للنشر و التوزيع.

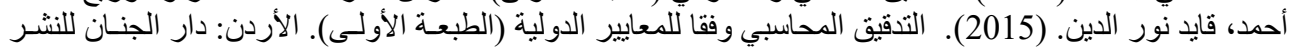

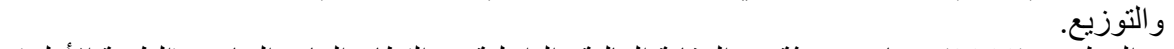

خالد، راغب الخطيب. (2010). مفاهيم حديثة في الرقابة المالية والداخلية في القطاع العام والخاص (الطبعة الأولى).

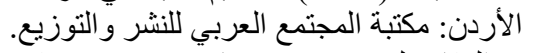

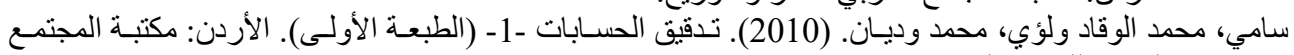
العربي للنشر وُوبي، التوزيع.

كمال، محمد سعيد كامل النونو. (2009). مدى تطبيق معايير التدقيق الداخلي المتعـارف عليهـا في في البنـوك الإسـلامية

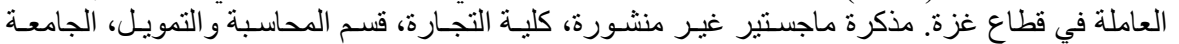

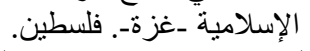
محمد، بريك. (1 مارس، الإس، 2015). مقابلة مع مساعد التدقيق الداخلي. مؤسسة مناجم الفوسفات تبسة.

\section{References}

IFACI. (Février 2004). Institut de l'Audit Interne, Normes internationales pour la pratique professionnelle de l'audit interne.

Pickett, KH. Spencer. (2003). The internal auditing handbook, $2^{\text {nd }}$ edition, Wiley, USA.

Khelassi, R. (2007). L'audit interne -Audit opérationnel-,2 $2^{\text {eme }}$ édition. Alger : Houma éditions Alger.

Djoumaa, A. H. (2009). The Introduction to Modern Audit and Confirmation ( $1^{\text {st }}$ ed.). Jordan: Dar Al-Safa for Publishing and Distribution. [In Arabic]

Djoumaa, A. H. (2011). Internal and Governmental Audit ( $1^{\text {st }}$ ed). Jordan: Dar Al-Safa for Publishing and Distribution. [In Arabic]

Gaid. A. N. (2015). Accounting auditing in accordance with international standards ( $\left.1^{\text {st }} \mathrm{ed}\right)$. Jordan: Dar Al-Jinan for Publishing and Distribution. [In Arabic] 
ممارسة التدقيق الداخلي على ضوء المعايير الدولية في المؤسسات الاقتصادية

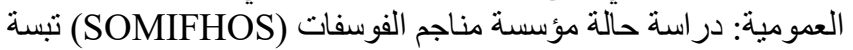

Al-Khatib, K. R. (2010). Modern Concepts in Financial and Internal Control in the Public and Private Sectors $\left(1^{\text {st }}\right.$ ed.). Jordan: Arab Society Library for Publishing and Distribution. [In Arabic]

Al-Waqqad, S. M., \& Wedyane, M. L. (2010). Auditing -1- (1st ed.). Jordan: Arab Society Library for Publishing and Distribution. [In Arabic]

Al-Nono, K. M. S. K. (2009). The extent of application of internal auditing standards recognized in Islamic banks operating in the Gaza Strip. (Master Thesis, Islamic University. Palestine). [In Arabic]

Brick, M. (March 1, 2015). Interview with the internal audit assistant. Phosphate Mines Corporation Tebessa. [In Arabic]

\section{The Practice of Internal Audit in the Light of International Standards in Public} Corporations: A Case Study of SOMIPHOS Corporation

Asma Maifi ${ }^{1 \bullet}$

Received: 15-11-2019

Accepted: $16-12-2019$

Published: 24-12-2019

\section{Abstract:}

This article aims to identify the extent of the commitment of the Algerian Public Economic Corporation to exercise the function of internal auditing in accordance with international standards issued by the Institute of Internal Auditors (The Institute of Internal Auditors) by introducing the concept of internal audit and then touch on the professional standards of internal audit issued by the Institute of Internal Auditors In light of the tasks and responsibilities related to them, and also how to organize this function in the institution and the foundations governing its organization The descriptive and analytical approach was used in the study by collecting data from various sources, the most important of which was interviewing the internal audit directors of SOMIFHOS based in Tebessa province as a public corporation to determine their compliance with international professional standards of internal auditing.

Keywords: Internal Auditing, International Internal Auditing Standards, Public Corporation.

JEL Classification: M42, J81.

1 Corresponding author: Farhat Abbas Setif University (Algeria),

[ $₫$ asma.maifi@gmail.com] 